\title{
Myectomy and mitral repair through the left atrium in hypertrophic obstructive cardiomyopathy: The preferred approach for contemporary surgical candidates?
}

\author{
Herbert Gutermann, MD, ${ }^{\mathrm{a}}$ Matteo Pettinari, MD, ${ }^{\mathrm{a}}$ Christiaan Van Kerrebroeck, MD, PhD, ${ }^{\mathrm{a}}$ \\ Margot Vander Laenen, MD, ${ }^{\mathrm{b}}$ Kim Engelen, MD, ${ }^{\mathrm{b}}$ Tom Fret, MD, ${ }^{\mathrm{b}}$ and Robert A. Dion, MD, PhD ${ }^{\mathrm{a}}$
}

\begin{abstract}
Objective: Patients with hypertrophic obstructive cardiomyopathy due to diffuse hypertrophy extending to or below the papillary muscles are poor candidates for alcohol septal ablation and suboptimal candidates for transaortic septal myectomy. In addition, the outflow obstruction is often aggravated by an abnormal mitral valve and subvalvular apparatus.
\end{abstract}

\begin{abstract}
Methods: We performed transatrial myectomy in 12 patients with diffuse hypertrophy, who were highly symptomatic despite maximal medical therapy. All had at least moderate mitral regurgitation and systolic anterior motion. The anterior mitral leaflet (AML) was detached from commissure to commissure, allowing an easy myectomy through this AML toward the base of the anterior papillary muscle, with mobility fully restored. The abnormal chordae from the septum to the anterior papillary muscle and AML were divided. The continuity of this AML was restored with augmentation using an autologous pericardial patch. The height of the posterior mitral leaflet was reduced and the repair completed using an oversized annuloplasty ring.
\end{abstract}

Results: The peak intraventricular gradients decreased spectacularly from $98.8 \pm 6.29$ to $19.2 \pm 13.4 \mathrm{~mm} \mathrm{Hg}$ $(P<.001)$, and the systolic anterior motion and mitral regurgitation disappeared. One patient died of left ventricular diastolic dysfunction. All other patients left the hospital in New York Heart Association class I or II.

Conclusions: We believe that this technique is preferable for patients with hypertrophic obstructive cardiomyopathy and diffuse hypertrophy extending to the midportion of the left ventricle or beyond. It results in disappearance of outflow tract gradients and allows correction of the mitral valve abnormality. (J Thorac Cardiovasc Surg 2014;147:1833-6)

Transaortic extended surgical septal myectomy (SSM) has generally been accepted as the preferred treatment of hypertrophic obstructive cardiomyopathy (HOCM) in patients with severe drug-refractory symptoms. This technique has been associated with very low mortality, consistent alleviation of outflow gradients and related symptoms, and excellent long-term survival. ${ }^{1}$

However, in recent years, the primary treatment strategy for typical asymmetric septal hypertrophy has, particularly in Europe, shifted toward percutaneous alcohol septal ablation (ASA), despite the suboptimal results in terms of complications, persistent symptoms, and the need for pacemaker implantation. $^{2}$ Thus, most contemporary surgical candidates will present with diffuse hypertrophy

\footnotetext{
From the Department of Cardiac Surgery ${ }^{\mathrm{a}}$ and Department of Anesthesia and Intensive Care, ${ }^{\mathrm{b}}$ Ziekenhuis Oost-Limburg, Genk, Belgium.

Disclosures: Authors have nothing to disclose with regard to commercial support.

Presented at The 2013 American Association for Thoracic Surgery Mitral Conclave,

New York, New York, May 2, 2013.

Received for publication April 29, 2013; revisions received June 24, 2013; accepted

for publication July 1, 2013; available ahead of print Aug 28, 2013.

Address for reprints: Robert A. Dion, MD, PhD, Department of Cardiac Surgery, Zie-

kenhuis Oost-Limburg, Schiepse Bos 6, Genk 3600, Belgium (E-mail: robert.

dion@zol.be).

0022-5223/\$36.00

Copyright (c) 2014 by The American Association for Thoracic Surgery

http://dx.doi.org/10.1016/j.jtcvs.2013.07.024
}

extending to or below the papillary muscles (PMs), with midcavity muscular obstruction. These patients are poor candidates for ASA but are also suboptimal candidates for the Morrow procedure.

In addition, the outflow obstruction in these patients will often be aggravated by an abnormal mitral valve and subvalvular apparatus. The PMs can be displaced anteroapically or can be attached, or even embedded, in the septal muscular hypertrophy. The posterior mitral leaflet (PML) is often longer with a diminished coaptation-septal distance. This results, together with a narrowed aortic-mitral angle, in systolic anterior motion (SAM) of the mitral valve. $^{3,4}$ Although the SAM causes mitral regurgitation (MR), great interindividual difference can occur for comparable degrees of SAM, depending on the geometry of the mitral valve and subvalvular apparatus. The incidence of some degree of MR in patients with HOCM has been reported to be up to $95 \%,{ }^{1}$ necessitating mitral valve repair in $20 \%$ of cases. ${ }^{4}$ Centers with a large experience have repeatedly shown a decrease in both SAM and MR with an adequately performed extended SSM. ${ }^{1,5}$ However, the persistence of SAM or MR after SSM can be difficult to predict, and treatment remains controversial, because mitral valve repair in the setting of HOCM can be challenging. 


\section{Abbreviations and Acronyms \\ $\mathrm{AML}=$ anterior mitral valve leaflet \\ ASA $=$ alcohol septal ablation \\ HOCM = hypertrophic obstructive cardiomyopathy \\ LVOT $=$ left ventricular outflow tract \\ $\mathrm{MR}=$ mitral regurgitation \\ PML = posterior mitral leaflet \\ $\mathrm{PM}(\mathrm{s})=$ papillary muscle $(\mathrm{s})$ \\ SAM $=$ systolic anterior motion \\ SSM = surgical septal myectomy}

\section{METHODS \\ Patient Selection}

From January 2010 to March 2013, we operated on 12 patients with diffuse obstructive hypertrophy. The indications for SSM included drugrefractory class III or IV symptoms $(\mathrm{n}=11)$, an episode of heart failure $(\mathrm{n}=1)$, and a blood pressure decrease of more than $10 \mathrm{~mm} \mathrm{Hg}$ at peak exercise $(n=3)$. One patient had undergone previous ASA.

\section{Patient Characteristics}

The mean patient age was $53.0 \pm 10.5$ years (range, 34-61), and $83 \%$ were men. All 12 patients had diffuse hypertrophy extending below the level of the PMs, with an average peak left ventricular outflow tract (LVOT) gradient of $98.8 \pm 6.29 \mathrm{~mm} \mathrm{Hg}$ and a mean septal thickness of $25 \pm 6 \mathrm{~mm}$. Most patients $(92 \%)$ had moderate to severe MR (mean $2.6 \pm 0.8$ ) and SAM. The color flow jet of the MR was either central or posteriorly directed, suggesting the SAM was responsible for the MR.

\section{Surgical Data}

All patients underwent surgery under normothermia, with a mean cardiopulmonary bypass time of $243 \pm 88$ minutes. Intermittent antegrade warm blood cardioplegia was administered every 15 minutes for 3 or more minutes. The mean aortic crossclamping time was $148 \pm 30$ minutes.

The mitral valve was exposed through a transatrial septal approach. The anterior mitral valve leaflet (AML) was detached from the annulus from commissure to commissure, providing excellent exposure of the septum to the apex of the heart. SSM was then performed, starting 5 $\mathrm{mm}$ under the aortic annulus just in the middle of the insertion of the AML. It was prolonged horizontally to the left to the limit of the outflow tract, with a depth of at least $1.5 \mathrm{~cm}$ less than the preoperatively measured depth. The myectomy was taken downward to the base of the anterior PMs over the same thickness, preferably in 1 block, using the combination of a no. 11 bladed knife and a stitch cutter, which allowed for easy appreciation of the resection depth. The mean depth of this muscle resection was $11.7 \pm 2.89 \mathrm{~mm}$. Starting the resection at the midpoint of the AML insertion prevents injury to the bundle of His, which is situated in the vicinity of the mitral posteromedial commissure. The anterior PM embedded in the hypertrophy was carefully mobilized, and abnormal chordae from the septum toward the anterior PM and AML were divided (Figure 1). The AML was reconstructed with an autologous untreated pericardial patch, generously sized in breadth and height to account for the stitching space, using a running locked 5-0 polypropylene suture (Pronova, Johnson \& Johnson, New Brunswick, NJ). If the height of the PML was more than $2 \mathrm{~cm}$ (92\% of cases), the PML was incised 5 $\mathrm{mm}$ from, and parallel to, the posterior annulus and resutured, reducing the height to approximately $1 \mathrm{~cm}$. The height of the "new" AML was measured, and a corresponding complete and semirigid ring (Physio II, Edwards LifeSciences, Irvine, Calif) was implanted, carefully avoiding undersizing (mean size, $34.0 \pm 1.6$ ).

\section{Statistical Analysis}

Statistical analyses were performed using Statistica statistical software (StatSoft, Tulsa, Okla). The results for the continuous data are reported as the mean \pm standard deviation or median and range, as appropriate. Paired $t$ tests were used to compare continuous parameters, and discontinuous data were compared using the Fisher exact test. $P<.05$ was considered statistically significant.

\section{RESULTS}

Intraoperative transesophageal echocardiography showed a reduction in the interventricular thickness from $25 \pm 6 \mathrm{~mm}$ to $15 \pm 3 \mathrm{~mm}(P<.001)$. There was no or trivial MR (grade, $0.71 \pm 0.49$ ), with a mean coaptation length of $9.2 \pm 0.7 \mathrm{~mm}$ and a posterior shift of the coaptation site, resulting in the complete disappearance of the SAM in all patients. Transthoracic echocardiography at discharge showed a spectacular alleviation of the peak intraventricular gradients $(98.8 \pm 6.29$ vs $19.2 \pm 13.4 \mathrm{~mm} \mathrm{Hg}, P<.001)$.

Patch augmentation of the AML is time-consuming; however, the longer aortic crossclamping time (mean, $148 \pm 30$ minutes) did not result in greater postoperative troponin $\mathrm{T}$ levels, despite the hypertrophy. In addition, the long aortic crossclamping time did not correspond to the ischemic time in our practice, because we have chosen to optimize the myocardial protection in these hypertrophic hearts by delivering warm blood cardioplegia for 3 to 4 minutes every 15 minutes. However, after unclamping the aorta, the suboptimal diastolic function required a precise optimization of the preload and, therefore, a longer reperfusion time.

In 1 patient, severe pulmonary hypertension persisted (preoperative systolic pulmonary artery pressure, $80 \mathrm{~mm}$ $\mathrm{Hg}$ ), with subsequent pulmonary edema immediately after weaning from cardiopulmonary bypass, necessitating the use of extracorporeal membrane oxygenation. He eventually died of left ventricular diastolic dysfunction and subsequent right ventricular failure. The other 11 patients were discharged after a median hospital stay of 15 days, and after 4 weeks, all were in New York Heart Association class I or II. One patient required a pacemaker for complete atrioventricular block (right bundle branch block was present after previous ASA).

\section{DISCUSSION}

The technique of leaflet extension (through the aortic valve) and transmitral myectomy have been previously described $^{6-8}$; however, we have used a combination of transmitral myectomy with the classic Carpentier techniques of mitral valve repair.

\section{Diffuse Hypertrophy With Embedded Papillary Muscles}

Despite the excellent long-term results and low complication rate of SSM, the use of ASA has continued to increase, especially in Europe. Therefore, contemporary 


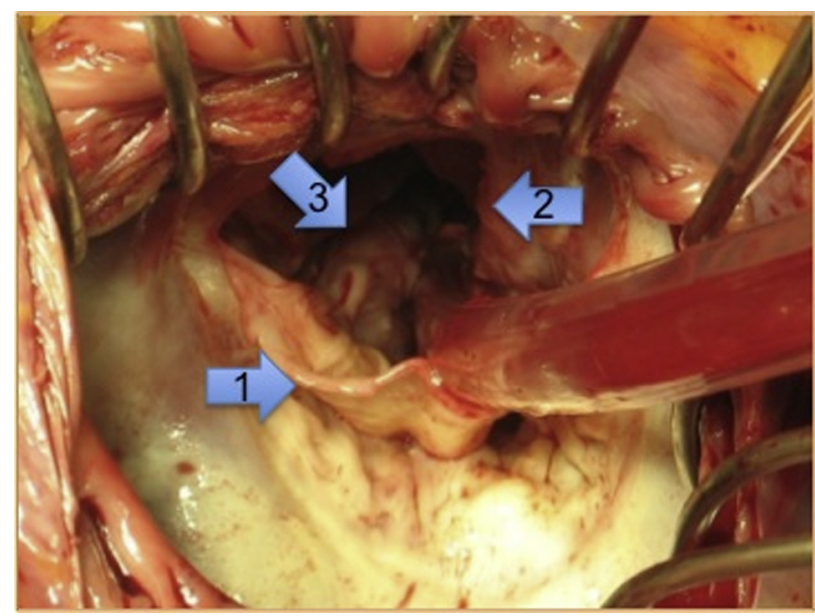

FIGURE 1. Intraoperative view. Arrow 1 indicates detached anterior mitral leaflet; arrow 2, septum resection started at the 12-o'clock position and extending toward the aortic valve; and arrow 3, the fully liberated anterior papillary muscle.

surgical candidates no longer present with the typical asymmetric hypertrophy, but with a diffuse form, extending to or below the PMs. Although some high-volume centers have reported transaortic extended myectomy down to the level of the PMs, going beyond and freeing them from the hypertrophic muscle remains very challenging through the aortic valve. In the case of apical or midventricular hypertrophy, some investigators have therefore promoted a transapical approach. ${ }^{9}$

With the transmitral approach, the myectomy can be easily extended to the apex, and the papillary muscles can be safely liberated from the ventricular wall under direct vision, restoring full mobility of the subvalvular apparatus. A transseptal approach ensures an optimal exposure of the mitral valve in such cases.

\section{Mitral Valve and Subvalvular Abnormalities}

In addition to septal hypertrophy, other contributors to dynamic LVOT obstruction have been described, in particular, mitral leaflet and subvalvular pathologic features. ${ }^{4,10}$
Abnormal papillary muscle morphology, including anteroapical displacement and bifid papillary muscles, has been associated with dynamic LVOT obstruction, independent of the basal septal thickness. ${ }^{4}$ Some investigators have promoted PM reorientation, fixing them to the posterior left ventricle to displace the leaflet coaptation posteriorly. ${ }^{4}$ A similar result, however, can be obtained by the combination of augmenting the AML and freeing the anterior PM.

The mitral leaflet length of the AML and/or PML will be abnormal on magnetic resonance imaging in $30 \%$ of patients with $\mathrm{HOCM},{ }^{3}$ making them extremely vulnerable for residual SAM, and the incidence of SAM after extended SMM can be up to $52 \% .^{1}$ An elongated PML is not infrequent and might be an acquired phenomenon, resulting from the Venturi suction of the mitral coaptation in the outflow tract.

Several techniques have been proposed to treat the aberrant mitral valve, such as retentionplasty, AML plication, the Alfieri stitch, and AML extension. ${ }^{6,10}$ The extension technique showed good results, with no SAM and a residual MI grade greater than I in 3\% of patients. ${ }^{6}$ The investigators hypothesized that this was because the patch stiffened the AML, making it less likely to buckle in the presence of Venturi and flow drag forces. In our technique, we have used a large untreated autologous pericardial patch, which is even weaker than the native leaflet. Therefore, in systole, the patch enlarges the outflow tract, eliminating the Venturi and drag forces, on the condition that complete deployment of this enlarged AML is possible (Figure 2) by freeing the anterior PM and reducing the PML height.

We have observed such a nice enlargement of the outflow tract that we have tended to become less aggressive with the myectomy. We also believe that valve replacement, even in the difficult setting of HOCM, can nearly always be avoided.

We had 1 perioperative death, for a mortality rate of $8 \%$ in this small study sample. However, these 12 patients did

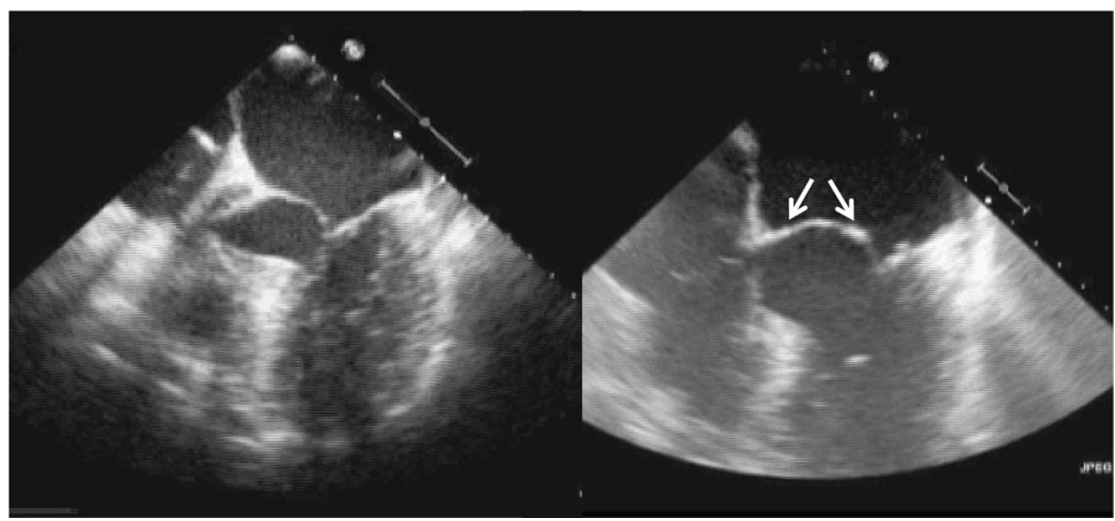

FIGURE 2. Transesophageal echocardiographic images before and after surgery. Note the bulging of the patch away from the left ventricular outflow tract (between arrows). 
not have classic HOCM with basal septal hypertrophy, for which we know that myectomy can be performed with almost no mortality. ${ }^{1}$ The patients in the present study all had diffuse hypertrophy of the left ventricle and therefore were prone to left ventricular diastolic dysfunction after myectomy.

\section{Study Limitations}

The present study lacked long-term follow-up data. However, the echocardiographic measurements showed a complete alleviation of the LVOT gradient, with a wide open outflow tract. The mitral repair used classic Carpentier techniques with their proven durability.

\section{CONCLUSIONS}

LVOT obstruction is multifactorial, and we do not believe that 1 technique is appropriate for all patients. We believe this technique is the treatment of choice for contemporary surgical candidates with diffuse hypertrophy extending to or below the level of the PMs.

\section{References}

1. Smedira NG, Lytle BW, Lever HM, Rajeswaran J, Krishnaswamy G, Kaple RK, et al. Current effectiveness and risks of isolated septal myectomy for hypertrophic obstructive cardiomyopathy. Ann Thorac Surg. 2008;85:127-33.
2. Alam M, Dokainish H, Lakkis N. Alcohol septal ablation for hypertrophic obstructive cardiomyopathy: a systematic review of published studies. J Interv Cardiol. 2006;19:319-27.

3. Maron MS, Olivotto I, Harrigan C, Appelbaum E, Gibson CM, Lesser JR, et al. Mitral valve abnormalities identified by cardiovascular magnetic resonance represent a primary phenotypic expression of hypertrophic cardiomyopathy. Circulation. 2011;124:40-7.

4. Kwon DH, Smedira NG, Thamilarasan M, Lytle BW, Lever H, Desai MY. Characteristics and surgical outcomes of symptomatic patients with hypertrophic cardiomyopathy with abnormal papillary muscle morphology undergoing papillary muscle reorientation. J Thorac Cardiovasc Surg. 2010; 140:317-24.

5. Wan CK, Dearani JA, Sundt TM III, Ommen SR, Schaff HV. What is the best surgical treatment for obstructive hypertrophic cardiomyopathy and degenerative mitral regurgitation? Ann Thorac Surg. 2009;88:727-31.

6. Van der Lee C, Kofflard MJ, van Herwerden LA, Vletter WB, ten Cate FJ. Sustained improvement after combined anterior mitral leaflet extension and myectomy in hypertrophic obstructive cardiomyopathy. Circulation. 2003;108: 2088-92.

7. Matsuda H, Nomura F, Kadoba K, Taniguchi K, Imagawa H, Kagisaki K, et al. Transatrial and transmitral approach for left ventricular myectomy and mitral valve plication for diffuse-type hypertrophic obstructive cardiomyopathy: a novel approach. J Thorac Cardiovasc Surg. 1996;112:195-6.

8. Casselman F, Vanermen H. Idiopathic hypertrophic subaortic stenosis can be treated endoscopically. J Thorac Cardiovasc Surg. 2002;124:1248-9.

9. Said SM, Schaff HV, Abel MD, Dearani JA. Transapical approach for apical myectomy and relief of midventricular obstruction in hypertrophic cardiomyopathy. J Card Surg. 2012;27:443-81.

10. Nasseri BA, Stamm C, Siniawski H, Kukucka M, Komoda T, Delmo WEM, et al. Combined anterior mitral valve leaflet retention plasty and septal myectomy in patients with hypertrophic obstructive cardiomyopathy. Eur J Cardiothorac Surg. 2011;40:1515-20. 